\title{
Modeling and Managing Shallow Lake Eutrophication
}

An overview of an IIASA book on the Lake Balaton Case Study by L. Somlyódy and G. van Straten

EXECUTIVE REPORT 10

March 1986 
Executive Reports bring together the findings of research done at IIASA and elsewhere and summarize them for a wide readership. This overview does not necessarily represent the views of the sponsoring organizations or of individual workshop participants. Copies of this Executive Summary can be obtained from the Publications Department, International Institute for Applied Systems Analysis, Schlossplatz 1, A-2361 Laxenburg, Austria.

\section{Copyright $\odot 1986$}

Sections of this publication may be reproduced in magazines and newspapers with acknowledgment to the International Institute for Applied Systems Analysis. Please send two tear sheets of any printed reference to this report to the Publications Department, IIASA, A-2361 Laxenburg, Austria. 


\section{CONTENTS}

1 The Eutrophication Problem 1

2 Shallowness 3

3 The Disciplines Interaction Gap 5

4 The Decomposition and Aggregation

Approach 7

5 Scientific Findings $\quad 9$

6 Handling Uncertainties 11

7 Water Quality Management 13

8 Conclusion 15

9 The Book 16

10 The Editors 19

11 Availability 20 

Man-made eutrophication has been recognized as the major problem that threatens the water quality and ecosystem of lakes throughout the world. Initially, disquieting changes in the lake's ecosystem were discernible only to specialists, such as freshwater ecologists and limnologists, but it was not long before massive algal blooms, discoloration, taste and odor problems, and occasional fish kills started to threaten public-user functions. Since then, both growing awareness of the importance of the function of ecosystems, in general, and adverse public reaction, in particular, have forced water managers to look for solutions to stop further deterioration and to implement measures that would ensure the restoration of the water quality of lakes in the long term.

Lake eutrophication control is not an easy task. Although there is general agreement that the exponentially increased nutrient loads that result from agriculture, urbanization, and industrialization are responsible, there are many differing options for their control, among which load reduction, for example by tertiary sewage treatment, is just one. The problem is multifaceted since the effects are visible in the lake, but the causes lie in the watershed and 
consequently to achieve a balanced control strategy requires a thorough analysis of the sources, transport routes, and lake ecosystem responses in order to assess the cost-effectiveness of the various alternatives. However, not only is such an analysis required; just as essential is the provision of a methodology to aggregate and reshape knowledge that is gained at the scientific level to make it useful for management application. The combination of these two aspects, analysis and synthesis, can be seen as the unique feature of the systems analysis study on shallow lake eutrophication conducted at IIASA, of which Modeling and Managing Shallow Lake Eutrophication is the outcome. 


\section{$\frac{2}{S H A L L O W N E S S}$}

In deep lakes, the algal organic matter produced in the photic zone sinks to deeper layers, where it is decomposed by bacterial action. During the summer, lake stratification prevents the nutrients released in the decomposition process from becoming available again to the primary production cycle and hence internal enhancement of the eutrophication process is postponed until after the autumn turnover, when environmental conditions for algal blooms are less favorable. In shallow lakes, where the hypolimnion buffer is absent, the eutrophication process can be more rapid and drastic. The shallowness makes the lake more vulnerable to variations in weather and nutrient inputs from runoff. Usually stronger irregularities, both within a year and on a year-by-year basis, are observed in shallow lakes as compared to deep lakes. In addition, the direct contact between the sediment and the productive water layer adds an extra dimension to the complexity of the nutrient cycle dynamics. All this may have contributed to the fact that the eutrophication control of shallow lakes has progressed less far and has been less successful than for deep lakes. Moreover, a 
comprehensive study of science-based eutrophication management of shallow lakes has been lacking thus far.

Rather than studying shallow lake eutrophication in general, it is more practical and fruitful to undertake a case study. Lake Balaton, Hungary, is the largest lake in Central Europe and is an almost ideal prototype for such a study. The lake exhibits unfavorable signs of artificial eutrophication, there is a vast amount of data, and considerable experimental research supports the development of systems models. Many phenomena that occur in Lake Balaton are also observed in other shallow lakes and, although no two lakes are ever really the same, the results can be considered representative of an approach that tackles the problem on the basis of practical experience gained with an actual case, so that it is truly likely to find application in other, similar eutrophication control studies. 
3

THE DISCIPLINES INTERACTION GAP

There are numerous publications on eutrophication in the scientific literature. However, most of these tackle the problem from one particular specialist viewpoint and, in general, a considerable lack of interaction and communication between the various disciplines is observed. For example, basic information about processes in lakes is provided by aquatic biologists and limnologists, but it has proved extremely difficult to convey these results to ecological modelers, partly because the information is frequently descriptive rather than quantitative and partly because there is no tool to decide what is important and what is not. The tendency in ecological modeling to respond to this by incorporating more and more species and components in the models is criticized by systems theoreticians, because such models are not identifiable from the existing data. On the other hand, systems engineers who try to induce models from field data have their particular bias in that they tend to ignore the existence of the vast amount of a priori knowledge available from biological studies. A similar communications gap can be observed between ecological modelers and hydrodynamicists, in which the first group almost completely ignores hydrodynamics, while the 
second tends to overemphasize the role of hydrodynamics in view of the time and space scales involved in ecological phenomena.

Even more striking is the confinement to discipline boundaries in the interaction between those working on in-lake problems and those concerned with the watershed. Generally, for in-lake studies nutrient inputs are simply taken as given inputs and hardly any analysis is given to the origin and nature of these inputs. Conversely, watershed transport and transformation processes are studied without much concern for the effects on the lake. In the study of water resources management the problem is usually very aggregated with virtually no interaction with process studies of the watershed or of the lake. 


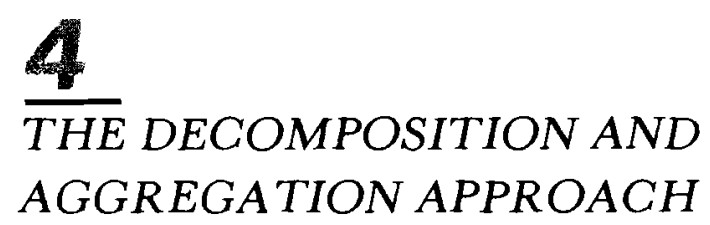

The method developed and described in this book attempts to overcome these difficulties. The principle employed is a logical sequence of decomposition and aggregation. The essence is that the system is first broken down into smaller units accessible to detailed, discipline-based analysis. The results of these analyses are then aggregated and only the essential features preserved for the subsequent part of the study - that is, the transition from the 'micro' to the 'macro' level. Thus, a pyramid of models is formed with the ultimate water-quality management model at the top. At this level the aggregated nutrient load model (the watershed) and the lake eutrophication model (the lake) are coupled, but a characteristic of the method is that this does not require the direct coupling of all the detailed models into one large model. In this way a framework is created that permits the simultaneous consideration of scientific and resource management issues, the handling of complexity, and the accommodation of various kinds of uncertainties.

First, in this approach an analysis is made of the detailed subprocesses that might be important to solving the problem. Examples are algal primary production, the sediment water interaction, lake 
circulation, watershed phosphorus load, etc. This stage of the process is research oriented and the principle objective is to gain insight and provide a thorough scientific basis for development of the model in the next stages.

The second step is concerned with modeling. In this stage there is a dichotomy as well: one part is concerned with the development of submodels, with which we try to simulate behavior under various conditions, and the other part is concerned with combining the submodels to work usefully together. Examples are lake eutrophication models and nutrient load models. Since, at this level, not every detail is needed, this process is concerned with simplification, but also a thorough analysis is made to analyze the effects of uncertainties. Uncertainties arise from model reduction, from data uncertainty, and from uncertainties in uncontrollable as well as controllable inputs. The result is that model predictions are not deterministic, but stochastic in nature.

In practice, the research and modeling steps are strongly interrelated, because modeling leads to notions of the relative importance of various subprocesses and also serves to elucidate black spots in the available knowledge. In the book we give several examples of this cross-fertilization between modeling and research.

In the third stage of the analysis the results of the research and modeling steps for the different sections of the problem are used to evaluate management alternatives. Again, rather than using the full simulation models, a strong aggregation is applied, again extracting the major features. This aggregation allows the use of optimization procedures and also allows a much more understandable transfer of information to policymakers, e.g., in the form of clear cost-benefit outcomes.

It should be stressed that the approach developed is sciencebased and ensures using as much information as possible, but in a form that is tractable to the level of management. A basic feature of the approach is that it looks for the relative importance of various processes, decisions, and policies in the entire problem without making a priori assumptions about them, while still remaining at a relatively low level of complexity. Model development is strongly goal-oriented and the limitations entailed by pragmatism are largely compensated by a science-based analysis of their impacts on policy options. 


\section{$\frac{\mathbf{5}}{\text { SCIENTIFIC FINDINGS }}$}

The detailed research on phytoplankton dynamics and nutrient uptake shows that this process is still far from being understood. The classical Monod description for phosphorus limitation appears to be just a very rough approximation of the true behavior. Experiments with a model in which the phosphorus-phytoplankton internal ratio is allowed to vary suggest that such models might give a better representation of dynamical behavior than the usual fixed stoichiometry models. In addition, occasional nitrogen limitation might complicate the dynamic behavior even further. All in all, at the scientific level much is still to be learned. However, the research also shows that these details have surprisingly little effect on the maximum algae concentrations predicted, the response being approximately linear with respect to the total load. The reason is that in phosphate-limited lakes, such as Lake Balaton, all the phosphate that enters the lake water is immediately taken up by the algae and the maximum standing crop is simply determined by the total phosphate available, irrespective of the pathway to this point.

In the light of this result the amount of phosphate generated internally in the lake from the lake's sediment becomes extremely 
important. Sediment research shows that both adsorption mechanisms and mineralization are important processes for the total release. Short-term dynamics are also influenced by resuspension and settling of particles due to wind action. This phenomenon, which is also important for the light intensity in the lake, has been modeled successfully. Both direct sediment research and modeling of the phytoplankton dynamics indicate that in the summer the internal load can be about the same as the external load. This implies that, in the short term, a complete cut in external load will leave algal peaks that are about one half the original level. Of course, from the point of view of management, this is not an attractive perspective. However, in the long term the response is governed by the recovery of the sediment, which depends upon the amount of phosphorus already stored in the sediment buffer. The results of the research suggest that readjustment of the sediment release to reduced nutrient loads can be fairly fast - about a couple of years - since most load reduction schemes result in a lower ratio of phosphorus load to adsorbent load, and so more phosphorus is immobilized in the sediment top layer. Consequently, the prospects for further algal level depression in response to load reductions are not as unfavorable as one would tend to believe from the short-term response calculations.

Study of the sources of external loads shows that sewage contributes roughly $50 \%$ of the available load. It also reveals that a major fraction of the particulate phosphorus load is transferred to the lake during storm-water events. A considerable portion of this phosphorus is not available for algal growth, but the part that is available probably originates from runoff of fertilizer phosphorus. The total phosphorus balance for the region shows that only a few percent of the phosphorus applied in the area reaches the lake. A considerable percentage is stored in the soil of the watershed, thus constituting a long-term potential danger to the lake.

The distribution of the load along the longitudinal axis of the lake is responsible for the longitudinal gradient of phosphorus, algae, and other constituents along the lake. The degree of mixing due to wind action is insufficient to level out these gradients. Hydrodynamical analysis shows that, in the case of Lake Balaton, a separation of the lake into four segments of different volume produces a correct longitudinal mixing behavior. The four-boxes model allows for a much simpler computation, at the cost of loss of some spatial detail. The separation proves particularly useful in evaluating the regions that should receive priority in abatement programs. 


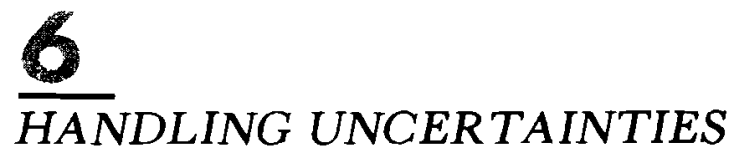

An important finding is that the behavior of the lake's algae is strongly influenced by climatic factors. Unfavorable conditions of temperature, solar radiation, and the like can compensate a large reduction in the nutrient load and the effectiveness of a load reduction program can be masked by such events. In fact, predictions using a stochastic input generator for both loads and climatic factors, based on historical data, show that annual chlorophyll-a peak concentrations in Lake Balaton can range between 30 and 150 $\mu \mathrm{g} / \mathrm{l}$. It is important to make a distinction between the runoff and the sewage components of the load, because the former influences mostly the variance of the annual algal peak sequence, whereas the latter predominantly influences the average level. These findings demonstrate the crucial role of uncertainty. In most studies published up to now no formal methodology has been offered to incorporate these uncertainties into the final management model.

The method developed incorporates a step to condense the information obtained from the dynamic lake model into nondynamic information suitable for decision making. The idea is that decisions are made on the basis of the behavior of some aggregated 
variables. In this case, the yearly peak chlorophyll-a concentration was selected as the target to be reduced. The transformation from a dynamic into a nondynamic, aggregated form was made possible by the observation that peak chlorophyll-a depended in a simple way on the nutrient load. The uncertainties due to uncontrollable weather conditions appeared in this function as a band around the nominal value. The average level of loads and load variability, resulting from the stochastic load model, are treated as controllable inputs to the stochastic management model. Thus, a framework has been created that maintains uncertainty information at a highly aggregated, nondynamic level and that then leads to a stochastic management model which can next be used in optimizing water management. 


\section{$\frac{7}{\text { WATER QUALITY MANAGEMENT }}$}

Using realistic data, both linear programming and stochastic programming with recourse were applied to calculate which control strategies would maximize the improvement in water quality for a given, fixed annual budget. The objective function combines both improvements in expectation as well as variance of the chlorophylla levels in the four basins. If relatively low budgets are available only, tertiary sewage treatment, starting from the basin with the highest volumetric loading, is the most cost-effective. The expected peak for chlorophyll-a drops from 75 to $55 \mathrm{mg} / \mathrm{m}^{3}$, but the extremes are still high; they fall from 140 to $120 \mathrm{mg} / \mathrm{m}^{3}$ only. Any further increase in budget, by five- or ten-fold, does not give substantial improvements in water quality. Beyond this point prereservoirs, such as sedimentation basins and reed belts, enter the solution and then the expectation of the annual algal peak drops further, from 55 to $40 \mathrm{mg} / \mathrm{m}^{3}$, whereas extremes fall drastically from 120 to $60 \mathrm{mg} / \mathrm{m}^{3}$. This result clearly demonstrates the importance of taking stochastic effects into account and also points out that high costs must be made if occasional, extreme peak chlorophyll-a concentrations are to be avoided. 
Another significant outcome is that if it is impossible to obtain a sufficiently accurate water-quality model in a particular study it would be wise to allocate control measures among the different sections of a spatially nonuniform lake according to the volumetric load distribution rather than the distribution of absolute loads. A sensitivity analysis of the management optimization model shows that, apart from the in-lake processes, other factors are equally important in the optimal solution. Among these are river retention coefficients, effluent standards, cost functions and their uncertainties, and capital recovery factors. Most notable is the finding that for lakes with spatially nonuniform water quality the prescription of fixed overall effluent standards is far from optimal. If the money saved by relaxing the standards in regions with a low volumetric load is spent in regions with a high volumetric load, a mu, $h$ better water quality can be achieved.

The question might arise whether these finding had any significant impact on the actual solution of the environmental problem of Lake Balaton. In many similar studies reported in the literature the answer is "no", but not so in this case. In fact, the sciencebased approach helped to properly understand the nature of the extremely heavy algal blooms that "unexpectedly" occurred during recent years, which resulted in a modification of the existing management plan according to the outcomes of the research. 


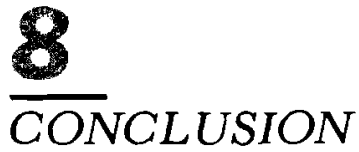

The gradually increasing pollution of lakes causes more and more water quality problems that need to be solved within a relatively short period of time. Insufficient ability to predict ecosystems behavior calls for further research, while at the same time direct measures are urgently required to prevent further dramatic changes in the ecosystem. So, both scientific and practical issues are important and a suitable procedure should give due account to both aspects. Modeling and managing lake eutrophication are not and should not be sequential processes, but rather they should be synchronized. This is the only way to achieve the integration of scientific results as soon as they become available, which leads to appropriate updates of management applications. In this book we show that an approach that harmonizes scientific research and management application can, indeed, be developed. For this reason it is worth examination by anyone who is concerned with the problem of lake eutrophication. 
$\frac{9}{\text { PURCHASING THE BOOK }}$

The book is divided into three parts. In Part One we describe the methodology. After an outline of the background to the Lake Balaton eutrophication problem chapters follow on the approach, on lake eutrophication models, and on eutrophication management models. Quite unusual for this sort of book, but highly interesting, is the chapter in which we demonstrate the impact of the study on policymaking at the governmental level in Hungary. Part One can be considered as containing the core of the results of the study. And although Lake Balaton is the object in this case, the method and approach are definitely of much wider interest.

In Part Two we deal with the description of processes and subsystems. Selected authors were invited to write these chapters, but a major effort was made by the editors to unify the various contributions. Topics discussed include the characteristics of nutrient loads, sediment and its interaction with water, phytoplankton changes during eutrophication and phosphorus and nitrogen metabolism, wind-induced water motion, and a coupled hydrophysical-ecological model. The contributions to this part of the book can be considered as reports on each of the specific issues 
on each of the specific issues that are needed for a complete understanding of the problem as a whole, but at the disciplinary level. A number of new ideas, hypotheses, and experimental findings are presented here.

In Part Three we cover a number of selected topics, chosen because of their originality or because of their implicit contribution to the success of the case study. Subjects to be found here are hypothesis testing and parameter uncertainty analysis in simple phytoplankton-phosphorus models, a complex model for simulating the Lake Balaton ecosystem, a comparison of water quality models and load reduction predictions, the role of the major tributary in the eutrophication of Lake Balaton, and the influence of watershed development on long-term eutrophication. Again, a number of methods, analyses, and ideas in these chapters are of broad interest and are applicable to other shallow lakes as well.

\section{CONTENTS OF THE BOOK}

\section{PART ONE: Problem, Methodology, and Management}

1 Background to the Lake Balaton Eutrophication Problem $L$. Somlyódy and G. van Straten

2 The Approach

$G$. van Straten and $L$. Somlyódy

3 Lake Eutrophication Models

G. van Straten

$4 \quad$ Eutrophication Management Models

L. Somlyódy

5 Impact on Policymaking: Background to

a Government Decision

I. Láng

PART TWO: Description of Processes and Subsystems

$6 \quad$ Nutrient Loads

L. Somlyódy and G. Jolánkai

7 Sediment and Its Interaction with Water

L. Lijklema, P. Gelencsér, F. Szilágyi, and L. Somlyódy 
8 Phytoplankton Changes During Eutrophication and $\mathrm{P}$ and $\mathrm{N}$ Metabolism

\section{S. Herodek}

9 Wind-Induced Water Motion P. Shanahan, D.R.F. Harleman, and L. Somlyódy

10 Lake Eutrophication Model: A Coupled Hydrophysical-Ecological Model

P. Shanahan and D.R.F. Harleman

\section{PART THREE: Selected Topics}

11

12

13

14

15
Hypothesis Testing and Parameter Uncertainty Analysis in Simple Phytoplankton-P Models $G$. van Straten

A Complex Model for Simulating the Lake Balaton Ecosystem

T. Kutas and S. Herodek

A Comparison of Water Quality Models and Load Reduction Predictions

R.A. Luettich, Jr. and D.R.F. Harleman

Role of the Zala River in the Eutrophication of Lake Balaton

O.Joó

The Influence of Watershed Development on the Long-Term Eutrophication of Lake Balaton L. Dávid and L. Telegdi

Index 
THE EDITORS

László Somlyódy is Director of the Research Centre for Water Resources Development (VITUKI) in Budapest, Hungary, and Director of the Institute for Water Pollution Control.

Gerrit van Straten is Senior Lecturer at the Department of Chemical Technology, Twente University of Technology, Enschede, The Netherlands, and Leader of the Environmental Systems Engineering Group. 
$\overline{A V A I L A B I L I T Y}$

The book Modeling and Managing Shallow Lake Eutrophication, which is summarized in this Executive Summary, was published in 1986 by Springer-Verlag. Copies are not available from IIASA, but may be obtained from your bookseller or directly from the addresses given below. The ISBN Numbers are ISBN 3-54016227-5 and ISBN 0-387-16227-5 (USA).

Springer-Verlag, Tiergartenstr. 17, D-6900 Heidelberg 1, FRG

Springer-Verlag New York Inc., 175, Fifth Ave., New York 10010, USA

Springer-Verlag Tokyo, 37-3, Hongo 3-chome, Bunkyo-ku, Tokyo 113, Japan

A bibliography of publications resulting from IIASA research on water-related problems is available free of charge from the Publications Department, International Institute for Applied Systmes Analysis, A-2361 Laxenburg, Austria. 